\title{
Authors' foreword:
}

The following study reports an experiment in which the effects of prosocial video game violence (saving hostages from terrorists) are compared against the effects of antisocial video game violence (murdering civilians in a mass shooting at an airport) on participants' helping behavior. The results are equivocal, and there are some ambiguities in the dataset: a number of subjects were excluded, and the results were examined once before the full sample was collected. (Among the authors, there is disagreement about whether a significant effect would have resulted in optional stopping.) Current resources do not permit us to conduct a second study at present. Thus, we publish this preprint so that our results are visible to any who might find them useful.

Peer review has made us aware of the following limitations: The results do not provide clear evidence of effects (or the absence of effects) of game violence. Additionally, the outcome is unusual and has unknown measurement properties. We note that the outcome was good enough for Cialdini et al. (1984), but their study used a small sample and they obtained relatively large $p$-values. Considered alongside the exclusions, the results are too ambiguous for publication in most peer-reviewed journals.

However, we feel we have learned something from our results. The results can rule out large and obvious effects of video game violence on helping behavior. Additionally, the results suggest that violence used during video game play for prosocial purposes does not substantially reduce prosocial behavior, and may even increase it relative to antisocial violence gameplay. We have also learned about the unusual distribution that this outcome yields. We hope that future studies on this topic will plan for greater sample sizes and use an outcome with more desirable properties.

Sincerely,

Adam Lueke

Joseph Hilgard

Ian Zimmerman

Bruce Bartholow

Bryan Gibson 
Hero violence in video games and prosocial behavior

Adam Lueke $^{\mathrm{a}}$, Joseph Hilgard ${ }^{\mathrm{b}}$, Ian Zimmerman ${ }^{\mathrm{c}}$, Bruce Bartholow ${ }^{\mathrm{d}}$, and Bryan Gibson ${ }^{\mathrm{e}}$ aDepartment of Psychological Science, Ball State University, Muncie, IN 47306 . Email: aklueke@bsu.edu (corresponding author)

bDepartment of Psychology, Illinois State University, Normal, IL 69710. Email: jhilgard@gmail.com

'Superior, WI 54880. Email: idzimme@gmail.com

${ }^{d}$ Department of Psychological Sciences, University of Missouri, Columbia, MO 65211. Email: bartholowb@missouri.edu

eDepartment of Psychology, Central Michigan University, Mt. Pleasant, MI 48859 47306. Email: gibso1b@cmich.edu 


\begin{abstract}
Research into violent videogames has yet to investigate how violence used in videogames for prosocial purposes could affect prosocial behavior. We assigned participants to one of three videogame conditions: an antisocial violence game, a prosocial violence game, or a control game. After gameplay, participants were dismissed from the experiment, but a confederate approached them in the hallway and asked them to help the Red Cross with a blood drive. Contrasts found that participants in the hero violence condition were more prosocial than those in the gratuitous violence condition, but these conditions did not differ from the control condition. This finding is discussed in light of several limitations of the study, including the nonnormal distribution of the dependent variable and issues related to the size of the final sample.
\end{abstract}

Keywords: video games, violence, prosocial behavior 


\section{Hero Violence in Video Games and Prosocial Behavior}

The potential effects of violent video game exposure on gamers have received considerable attention in recent years. The published scientific literature generally supports the conclusion that violent video games increase aggressive behavior (Anderson et al., 2010; Greitemeyer \& Mugge, 2014), and the majority of researchers agree that this effect is real and well substantiated (Anderson et al., 2015; Bushman, Gollwitzer, \& Cruz, 2015). Violent video game effects have been found to increase aggression immediately after playing in a number of different ways using different measures of aggression (Anderson \& Dill, 2000; Bartholow \& Anderson, 2002; Bartholow, Bushman, \& Sestir, 2006; Engelhardt, Bartholow, Kerr, \& Bushman, 2011; Fischer, Kastenmuller, \& Greitemeyer, 2010; but see McCarthy, Coley, Wagner, Zengel, and Basham, 2016, for a null result in a preregistered setting). These effects are not limited to the time period immediately following violent video game exposure, but can remain even 24 hours later (Bushman \& Gibson, 2011), as evidenced by men who were more aggressive after returning the day after playing a violent video game with the instruction to ruminate about it.

Most studies show that violent game exposures as brief as 20 minutes are sufficient to increase players' aggression. When examining long-term exposure, evidence indicates that sustained violent video game exposure over time is related to increased aggressive behavior, with greater exposure relating to greater levels of aggression (Hull, Brunelle, Prescott, \& Sargent, 2014; Willoughby, Adachi, \& Good, 2012). In addition, playing violent video games has been linked to desensitization toward arousing stimuli (Bailey \& West, 2013; Bailey, West, \& Anderson, 2011; 
Bartholow, Bushman, \& Sestir, 2006; Carnagey, Anderson, \& Bushman, 2007;

Engelhardt, Bartholow, Kerr, \& Bushman, 2011), perception of one's own aggressive behavior as less aggressive (Greitemeyer, 2014), and increased interpretation of aggression in others (Bushman \& Anderson, 2002).

Comprehensive meta-analytic reviews including various methodologies have supported the theory that violent video game playing causes negative effects in a number of domains related to aggression (Anderson et al., 2010; Greitemeyer \& Mugge, 2014). However, these reviews are not without controversy. Effects of violent games on aggressive behavior in experiments appear to be overestimated by publication bias, although the degree of bias is yet unclear (Hilgard, Engelhardt, and Rouder, 2017; Kepes, Bushman, and Anderson, 2017). There is, accordingly, a need for further research, transparently reported and published, on the effects of violent games.

Of particular importance to the current study is the negative effect violent video games and activated mental content may have on prosocial behavior. Elevated aggressive behavior following violent video game play is thought to be the result of the activation of aggressive concepts, according to the General Aggression Model (see Anderson \& Bushman, 2002). Research has reported that playing violent video games also increases the latency with which one helps others (Bushman \& Anderson, 2009), notably by reducing empathic concern for others (Fraser et al., 2012; You, Kim, \& No, 2015). On the other hand, research with prosocial video games, in which the player does nice things (or life-saving things) to or for other game characters, indicates that playing these types of games actually increases prosocial behavior (Gentile et al., 2009; more), likely by increasing access to prosocial thoughts (Greitemeyer \& Osswald, 2010; 
Greitemeyer \& Osswald, 2011; but see Tear and Nielsen, 2013 for a failure to replicate). Thus, results have indicated that the activation of prosocial or aggressive constructs through exposure to congruent content in video games influences future behavior. So, depending upon the type of behavior engaged in while playing the game, gamers may either have more prosocial constructs activated following gameplay, making them more inclined toward compassion and helping, or they may have more aggressive constructs activated following gameplay, making them more inclined toward anger and aggression.

Interestingly, there are certain games in which both constructs are intertwined within the game's objectives. Some video games require violence in order to help save innocent people, or even the world, against those attempting to do harm. Many games require the player to save innocents from monsters, terrorists, or even Nazis. Thus, players must be violent, which may reduce prosocial behavior, but within the plot of the game the violence is in the service of helping others, which may increase prosocial behavior. Interestingly, research has shown that playing a violent video game cooperatively with other players increases prosocial behavior (Ewoldsen, Eno, Okdie, \& Velez, 2012), so there is evidence to suggest that prosocial contexts around a violent video game can produce prosocial effects. However, the objective of cooperative violent game play is usually simply to win, not to act prosocially per se. To this point, no research has investigated the effects that violent games with prosocial objectives may have on prosocial behavior. If it were merely the case that violent video game content reduced prosocial behavior, and prosocial video game content increased it, then perhaps the two effects would generally cancel each other out, resulting in neither an increase or decrease in prosocial behavior. However, it is possible that prosocial 
violence in video games will activate a prosocial concept that would produce increased prosocial behavior when given the opportunity and context to do so.

Of crucial importance in our conception of the nature of these effects is the fit between the behavioral context available to players and the constructs activated within the video game. Thus, violence within the game that was carried out in order to save lives may lead to increased aggression in a subsequent context in which aggression is viable. In contrast, we propose that if the context instead allows for prosocial behavior, then that behavior, too, would be more likely. To further explore the extent to which a match between constructs activated within the game and subsequent behavioral options might affect behavior, we also included a manipulation that would, for some participants, highlight the opportunity to "help save lives". We hypothesized that such a statement could potentially tap more directly into constructs activated by participants who had just played a game with the goal of saving lives, thereby increasing prosocial behavior.

We hypothesize that the prosocial nature of the violence in a video game scenario in which players must kill in order to save innocent hostages will increase the tendency to be prosocial when given the opportunity. This could be especially true when the nature of the helping opportunity is phrased in a way that matches the nature of the prosocial behavior in the violent video game, namely in order to save lives. Players who play this type of game will be significantly more prosocial after the game has ended than players of a video game in which violence is gratuitous, and also significantly more prosocial than players of a control game.

\section{Method}


We report how we determined our sample size, all data exclusions (if any), all manipulations, and all measures in the study (Simmons, Nelson, Simonsohn, 2012). All materials and deception were reported to the Institutional Review Board for approval.

\section{Participants}

Participants were (235) college students (44\% male) from two large, Midwestern universities. The study was advertised as an investigation as to how video games relate to both enjoyment and emotion, with the statement that participants would simply play a video game and then answer some questions about how much they enjoyed playing it and what kinds of emotions they experienced during their gameplay. All participants were traditional college aged students. A sample size of 40 participants per condition was judged sufficient to achieve adequate statistical power.

\section{Materials and Procedure}

Participants were randomized (by sampling to a quota per cell) to a 3 (Game: Gratuitous violence, Hero violence, No violence) $\times 2$ (Help Red Cross, Save lives) between-subjects design.

When participants first entered the lab, one of three different video games was awaiting them. In the "Gratuitous Violence" condition, participants played a level in Call of Duty: Modern Warfare entitled "No Russian", in which the participant controlled a character who is a US special ops member that is undercover as part of a terrorist organization that walks into an airport and has to kill innocent civilians and police officers. However, manipulation of the intro video to the game's level made it appear that they were merely a part of the terrorist organization. Participants in the "Hero Violence" condition played a different level in Call of Duty: Modern Warfare entitled "The 
Only Easy Day Was Yesterday". In this level, participants were first told in the intro video that some innocent crew members of an oil rig were being held captive by a terrorist organization, and it was the job of the participant to sneak onto the oil rig and save the hostages. Success in this level required killing many of the terrorist members while freeing the hostages. Before playing either of these Call of Duty levels, participants in both conditions warmed up to the controls during a 5-minute training level at the beginning of the Call of Duty campaign that systematically shows participants how the controller works and allows them time to practice with the controller. In the control condition, participants played Gran Turismo, in which they were required to race other computer controlled cars. Before they proceeded to race, participants received instruction on the use of the controller, and were allowed to practice for five minutes on a time trial track with no other cars. In all three of these conditions, participants completed the training session, and then immediately began playing their assigned game condition for 15 minutes.

After gameplay ended, participants completed questionnaires on a computer for approximately $10 \mathrm{~min}$. They first completed the PANAS (Watson, Clarke, \& Tellegen, 1988), followed by several questions regarding their gameplay experience. These questions included experience of enjoyment playing the game, how often the participant played video games, and if the genre of game they played was the genre they normally would enjoy playing. Participants were then asked demographic questions and questions to probe for suspicion, before being told that they had completed the experiment. They were then given a fake debriefing statement. This statement told 
participants that we were interested in how video game experience affected enjoyment and mood. Participants then left the lab.

As participants walked down the hall to the exit, they were greeted by a female confederate, who was blind to the gaming condition. She posed as a member of the Red Cross looking for people to volunteer their time to help with a blood drive (as originally used by Manucia, Baumann, \& Cialdini, 1984). When she stopped the participant in the hall, she recited the following: "Hi - my name is Sara with the Red Cross. We are currently looking for volunteers to call previous blood drive donors to see if they would be willing to donate again at the present time. If you choose to volunteer, you would choose anywhere from one to 20 individuals to call, and we would provide you a list of individuals that you would contact and inquire into their willingness to donate again. Your participation could really help out our blood drive. Would you be willing to volunteer?" Depending upon which condition they were assigned, some participants heard the confederate say "Your participation could really save some lives" instead of "Your participation could really help out our blood drive". Everything else in the script was identical. If the participant responded "yes", then the confederate asked how many people the participant would volunteer to call. After this point, or after the participant had declined to volunteer, the confederate told the participant that she was part of the experiment, and asked if the participant had any suspicions of this. Following this acknowledgment, the confederate then debriefed participants as to the real purpose of the experiment to see how types of video games may affect prosocial behavior and asked if the participant had any questions. At this point the experiment ended, and the participant was thanked and left. 


\section{Sample}

An initial data collection included 216 subjects, 191 of which were successfully intercepted by the confederate as they left the laboratory. During data collection, the Spring semester ended before data collection was completed. We looked at the data to examine whether patterns were trending in the hypothesized direction, with the idea that we would continue data collection up to our pre-planned sample size if they were (at which point we would stop), and would drop data collection if they were not. The data were indeed trending in the hypothesized direction, so we picked up data collection as originally planned in the following Fall semester. This natural pause in data collection and evaluation of whether or not to continue collecting data may or may not influence Type I error rates. Additionally, we decided to exclude a semester's worth of participants from one study site ( $n=31,21$ of which were intercepted) because the confederate (used for only that semester) failed to properly collect the data (e.g. she often did not show up when participants were signed up, failed to intercept them in the halls, entered zeros for participants' blood drive donations when she failed to intercept in them in the halls). To support this exclusion of the data, we found the participants solicited by this confederate were statistically less likely to volunteer than other participants, $x 2(1)=$ $4.02, p=.045$. This left us with a final sample of 204 participants, 189 of which were successfully intercepted by the confederate.

Our primary analyses concern this final sample. However, to explore the robustness of our results, we also analyze the data including those 31 excluded participants. 


\section{Distribution}

Initial inspection of the data revealed pronounced non-normality (Figure 1). Many subjects did not offer to make any calls, and among those who did, the number of calls offered was strongly right-skewed and favored multiples of 5 .

This non-normality creates ambiguity in what might be the most appropriate model to fit. Although ANOVA is commonly used and fairly robust to outliers, its underlying assumptions are violated by the pronounced non-normality of the residuals (see Glass, Peckham, \& Sanders, 1972). Therefore, we fit alternative models to explore the robustness of the results and to characterize their analytic ambiguity. In total, we fit: 1) ANOVA; 2) logistic regression, testing whether condition affected the odds of volunteering to make any calls; 3 ) a chi-squared test, again testing whether condition affected the odds of volunteering to make any calls; 4) a zero-inflated negative binomial, which accounts for the frequent zero-responses and the strong right skew; and 5) a non-parametric Kruskal-Wallis test for differences in the median. Results for each model are reported separately, then synthesized and summarized at the end.

ANOVA. ANOVA indicated a significant effect of game, $F(2,183)=3.20, p=$ .043. Neither the effect of request nor the Game $\times$ Request interaction was statistically significant, $F(1,183)=1.27, p=.262$ and $F(2,183)=0.00, p=.996$, respectively.

Collapsing across levels of request, a contrast between the prosocial-violence and antisocial-violence conditions was statistically significant, $t(122)=2.48, p=.015, b$ $=2.02[.40,3.63]$. Neither game significantly differed from control. 
Logistic GLM. To test whether the game influenced the odds of volunteering, we collapsed observations to a binomial outcome $(0=$ did not volunteer, $1=$ volunteered $)$. A logistic GLM was fit to test for effects of game condition and request.

The effect of game was not statistically significant, but not especially far from significance, either, $X^{2}(2)=5.09, p=.079$. Effects of request and the Game $\times$ Request interaction were not statistically significant, $X^{2}(1)=0.85, p=.358$ and $X^{2}(2)=0.11, p=$ .948 , respectively.

Again, the contrast between the prosocial-violent and antisocial-violent games was statistically significant, $z=2.00, p=.029, O R=2.31[1.1,4.96]$. However, neither game significantly differed from control.

Chi-squared test. A chi-squared test was used to test whether the probability of volunteering at all differed across game conditions (collapsing across levels of request). The omnibus test for game type was not significant, but not far from significance, $x 2(2)$ $=4.97, p=.083$. As in other analyses, the contrast between prosocial-violent and antisocial-violent was just significant, $\mathrm{X} 2(1)=4.07, p=.044$, although neither game significantly differed from control.

Zero-inflated negative binomial. A zero-inflated negative binomial was then fit to the data. This model has two parts: The zero-inflation model, which estimates whether participants volunteer at all, and the count model, which estimates how many calls they offer when they do volunteer.

Because we did not have reason to expect the game would influence only the zero-inflation model or only the count model, we tested the overall effect of game on both parameters simultaneously with likelihood-ratio chi-square tests. The effect of 
game was ambiguous, neither statistically significant nor particularly far from significance $\left(x^{2}(4)=7.92, p=.095\right)$. Effects of request $(x 2(2)=4.27, p=.118)$ or the Game $\times$ Request interaction $(X 2(4)=0.96, p=.916)$ were not significant. The overdispersion parameter was highly significant $(z=4.61, p<.001)$, supporting the use of the negative binomial over a zero-inflated Poisson distribution.

A pairwise contrast between the prosocial-violent and antisocial-violent games yielded a significant effect of game, $x 2(2)=6.67, p=.036$. Tests of individual parameters found a significant difference on the zero-inflation parameter $(z=-2.17, p=$ $.030)$ but not on the count parameter $(z=1.30, p=.193)$. Again, neither game differed from control.

Kruskal-Wallis test. The Kruskal-Wallis test is a nonparametric test of group medians. Because the test is only applicable to one-way ANOVA designs and the primary hypothesis regarded effects of game, we collapsed across levels of request and tested for an effect of game. As in other analyses, the omnibus effect of game was not statistically significant, but not far from significance, $x 2(2)=5.09, p=.079$.

The pairwise contrast between the antisocial and prosocial violent games was statistically significant, $X 2(1)=4.97, p=.026$. However, neither game significantly differed from control, $p=.224, .262$. 


\section{Describing uncertainty}

Uncertainty across models. Figure $2 \mathrm{~A}$ shows the distribution of omnibus test $p$ values across the five models. Figure $2 \mathrm{~B}$ shows the distribution of pairwise prosocial/antisocial game contrast $p$-values across the five models.

Across models, the omnibus test is generally not statistically significant (median $p=.079$ ), reaching a minimum $p$-value of .043 in the ANOVA model. The pairwise contrast, on the other hand, is statistically significant. Its $p$-values range from .015 (ANOVA) to .044 (chi-squared test), with median $p=.029$.

Uncertainty across datasets. In the analyses presented above, 31 participants were excluded after it was found that the confederate at one site during one semester was not collecting data as instructed. One may wonder how robust the results are to the inclusion of these subjects. Figure 3 shows the variability in the $p$-value across this decision to include or exclude. Six parameters in two datasets yields twelve $p$-values. Figure $3 \mathrm{~A}$ shows the distribution of omnibus test $p$-values, and Figure 3B shows the distribution of pairwise contrast $p$-values across the five models.

Together, these figures illustrate the uncertainty in the $p$-value across datasets. Again, we note that only one analysis yielded a significant omnibus test. Additionally, some of the pairwise contrasts are no longer statistically significant when including the 31 subjects of questionable quality. Naturally, bad data should be excluded. Still, to the extent that this decision was made ad hoc, it is useful to note their influence on the $p$ value. 


\section{Bayesian ANOVA}

One last way to consider the results would be through a Bayesian ANOVA. Like the frequentist ANOVA presented above, this model suffers from violated assumptions of normally distributed residuals. However, it does have the advantage of appraising the evidence in terms of continuous odds rather than the dichotomy of statistical significance. Effects were tested using the anovaBF() function in the BayesFactor package (Morey \& Rouder, 2015) using a Cauchy prior with scale parameter 0.4, consistent with effects typical of social psychology.

These ANOVAs indicated ambiguous evidence regarding an omnibus effect of game, 1.15:1 odds in favor of $\mathrm{H} 1$ over $\mathrm{H} 0$. Odds in favor of the prosocial/antisocial game contrast were stronger, but still marginal at 2.96:1 in favor of $\mathrm{H} 1$ over $\mathrm{H} 0$. When including the 31 subjects of questionable quality, these ANOVAs indicated 1.94:1 odds against an omnibus effect of game and 1.44:1 odds in favor of a prosocial/antisocial game contrast. This Bayesian approach indicates that the results are ambiguous and that neither $\mathrm{H} 1$ nor $\mathrm{H} 0$ is a clear winner, consistent with the other analyses presented above.

\section{Discussion}

We generally did not detect a significant overall effect of game on prosocial behavior. Still, pairwise contrasts suggested a significant difference in behavior following the prosocial-violent as compared to the antisocial-violent game. However, this contrast should be interpreted with caution given that neither violent game significantly changed behavior relative to the control game. Evidence was generally equivocal, as indicated by the Bayesian ANOVA. 
Considerable uncertainty remains. The decision to exclude subjects is justifiable, but not based on any a priori rule, creating another researcher degree of freedom. The prosocial-violence vs. antisocial-violence contrast is one of three potential contrasts that consider the effects of game. Finally, the omnibus results are a little sensitive to the particular model applied. Whereas a typical manuscript might conceal the ambiguity by presenting just one analysis, here we find it most helpful to show all possible analyses.

This uncertainty should not be mistaken for an argument that games do not influence prosocial behavior. Although statistical significance is sporadic and sensitive to choice of model, contrast, or inclusion rules, it is generally not the case that the results constitute support for the null hypothesis. To that point, all contrasts from our final sample regarding the prosocial-violence and antisocial-violence conditions revealed that prosocial-violence game players were significantly more prosocial than anti-social violence game players.

The results of this study are helpful in estimating the effects of antisocial-violent and prosocial-violent games. It is unclear whether these types of games differ from control games in their effects on prosocial behavior. If such effects exist, they are likely not large and obvious, at least using this particular dependent measure. Furthermore, we are able to rule out some effects of the opposite direction. The data are inconsistent with antisocial-violent games promoting prosocial behavior or prosocial-violent games inhibiting prosocial behavior.

The prosocial measure used in the current study was a considerable limitation. Several of the participants that completed the lab portion of the study were missed by the confederate, so they were unable to encounter the prosocial portion of the 
experiment. Additionally most participants declined to volunteer, causing something of a floor effect. A prosocial measure in which most participants are willing to help at least a little bit would be more sensitive. This would also be more effective in testing potential decreases in prosocial behavior, as the control group mean would be further from the floor. Better psychometric properties would also provide a better test of potential increases in prosocial behavior following a violent-prosocial game.

In conclusion, despite collection of a moderately-sized sample, the results are ambiguous regarding whether prosocial-violent and antisocial-violent games affect prosocial behavior as compared to a nonviolent game. Some support for a difference between antisocial and prosocial violent games was found, but this difference was sensitive to the choice of dataset, as the inclusion of bad data collected by one confederate minimized differences. Future research is encouraged to test the effects of prosocial, antisocial, violent, and nonviolent games on prosocial behavior. This research program would be facilitated by the development of more sensitive and model-friendly measures of prosocial behavior, perhaps such as the Tangram help/hurt task (Saleem, Anderson, \& Barlett, 2015).

In particular, with a better measure of prosocial behavior, the current ambiguous results that provide some tentative support for the difference between prosocial-violent and antisocial-violent could be clarified. It is possible that violent video games reduce prosocial behavior, whereas the prosocial element of violent video games may counteract the violent nature of the game, which would result in similar prosocial behavior to a control game. On the other hand, it is possible that the prosocial element of a violent video game increases prosocial behavior above an antisocial violent game, 
which may or may not be different from a control game. Another possibility is that a prosocial violent video game encourages both prosocial behavior and aggression, but the context determines which of those responses would be elicited. For instance, after playing a prosocial violent game, the prosocial element of the game may influence players to help an elderly person across the street, while the violent element of the game may influence the player to yell at someone in a car that impatiently honks at the delay. Future research should work to disentangle all of these possibilities and further enhance our understanding of the potential different effects that antisocial violence and prosocial violence may have on the gamer.

\section{Data Availability}

Data and analytic code are available at https://github.com/Joe-Hilgard/hero-violence.

\section{Competing Interests}

We have no competing interests.

\section{Authors' Contributions}

Adam Lueke created the design, collected data, and wrote the manuscript. Joe Hilgard conducted all analyses and helped write the manuscript. Ian Zimmerman collected data, organized data, and helped write the manuscript. Bruce Bartholow collected data and helped write the manuscript. Bryan Gibson created the design, collected data, and helped write the manuscript. All authors engaged in discussions regarding the analyses and construction of the manuscript, and all authors gave final approval for publication.

\section{Funding}

No funding supported this research. 


\section{Research Ethics}

This study received approval from the Institutional Review Board at both Central Michigan University and the University of Missouri. Participants gave informed consent to participate in this study.

\section{Animal Ethics}

We were not required to complete an ethical assessment in this area to conduct our research.

\section{Permission to Carry Out Fieldwork}

No permissions were required to conduct our research.

$$
\text { Acknowledgments }
$$

No acknowledgments.

\section{References}

Anderson, C. A., Andrighetto, L., Bartholow, B. D., Begue, L., Boxer, P., Brockmyer, J. F., . . Warburton, W. (2015). Consensus on media violence effects: Comment on Bushman, Gollwitzer, and Cruz (2015). Psychology of Popular Media Culture, 4(3), 215-221. doi:http://dx.doi.org.cmich.idm.oclc.org/10.1037/ppm0000063

Anderson, C. A., \& Dill, K. E. (2000). Video games and aggressive thoughts, feelings, and behavior in the laboratory and in life. Journal of Personality and Social Psychology, 78(4), 772-790.

doi:http://dx.doi.org.cmich.idm.oclc.org/10.1037/0022-3514.78.4.772

Anderson, C. A., \& Bushman, B. J. (2002). Human aggression. Annual Review of Psychology, 53, 27-51. Retrieved from 
http://cmich.idm.oclc.org/login?url=http://search.proquest.com.cmich.idm.oclc.org /docview/60451427?accountid=10181

Anderson, C. A., Shibuya, A., Ihori, N., Swing, E. L., Bushman, B. J., Sakamoto, A., . . Saleem, M. (2010). Violent video game effects on aggression, empathy, and prosocial behavior in eastern and western countries: A meta-analytic review.Psychological Bulletin, 136(2), 151-173.

doi:http://dx.doi.org.cmich.idm.oclc.org/10.1037/a0018251

Bailey, K., \& West, R. (2013). The effects of an action video game on visual and affective information processing. Brain research, 1504, 35-46.

Bailey, K., West, R., \& Anderson, C. A. (2011). The association between chronic exposure to video game violence and affective picture processing: an ERP study. Cognitive, Affective, \& Behavioral Neuroscience, 11(2), 259-276.

Bartholow, B. D., \& Anderson, C. A. (2002). Effects of violent video games on aggressive behavior: Potential sex differences. Journal of Experimental Social Psychology, 38(3), 283-290. Retrieved from

\section{http://cmich.idm.oclc.org/login?url=http://search.proquest.com.cmich.idm.oclc.org} /docview/619875486?accountid=10181

Bartholow, B. D., Bushman, B. J., \& Sestir, M. A. (2006). Chronic violent video game exposure and desensitization to violence: Behavioral and event-related brain potential data. Journal of Experimental Social Psychology, 42(4), 532-539. Retrieved from http://cmich.idm.oclc.org/login?url=http://search.proquest.com.cmich.idm.oclc.org /docview/621352842?accountid=10181 
Bushman, B. J., \& Anderson, C. A. (2002). Violent video games and hostile expectations: A test of the general aggression model. Personality and Social Psychology Bulletin, 28(12), 1679-1686. Retrieved from http://cmich.idm.oclc.org/login?url=http://search.proquest.com.cmich.idm.oclc.org /docview/214004303?accountid=10181

Bushman, B. J., \& Anderson, C. A. (2009). Comfortably numb: Desensitizing effects of violent media on helping others. Psychological Science, 20(3), 273-277. Retrieved from http://cmich.idm.oclc.org/login?url=http://search.proquest.com.cmich.idm.oclc.org /docview/37257436?accountid=10181

Bushman, B. J., \& Gibson, B. (2011). Violent video games cause an increase in aggression long after the game has been turned off. Social Psychological and Personality Science, 2(1), 29-32. doi:http://dx.doi.org.cmich.idm.oclc.org/10.1177/1948550610379506

Bushman, B. J., Gollwitzer, M., \& Cruz, C. (2015). There is broad consensus: Media researchers agree that violent media increase aggression in children, and pediatricians and parents concur. Psychology of Popular Media Culture, 4(3), 200-214. doi:http://dx.doi.org.cmich.idm.oclc.org/10.1037/ppm0000046

Carnagey, N. L., Anderson, C. A., \& Bushman, B. J. (2007). The effect of video game violence on physiological desensitization to real-life violence*. Journal of Experimental Social Psychology, 43(3), 489. Retrieved from http://cmich.idm.oclc.org/login?url=http://search.proquest.com.cmich.idm.oclc.org /docview/214790373?accountid=10181 
Engelhardt, C. R., Bartholow, B. D., Kerr, G. T., \& Bushman, B. J. (2011). This is your brain on violent video games: Neural desensitization to violence predicts increased aggression following violent video game exposure. Journal of Experimental Social Psychology, 47(5), 1033-1036. Retrieved from http://cmich.idm.oclc.org/login?url=http://search.proquest.com.cmich.idm.oclc.org /docview/864618359?accountid=10181

Ewoldsen, D. R., Eno, C. A., Okdie, B. M., Velez, J. A., Guadagno, R. E., \& DeCoster, J. (2012). Effect of playing violent video games cooperatively or competitively on subsequent cooperative behavior. Cyberpsychology, Behavior, and Social Networking, 15(5), 277-280. doi:http://dx.doi.org.cmich.idm.oclc.org/10.1089/cyber.2011.0308

Fischer, P., Kastenmüller, A., \& Greitemeyer, T. (2010). Media violence and the self: The impact of personalized gaming characters in aggressive video games on aggressive behavior. Journal of Experimental Social Psychology, 46(1), 192-195. doi:http://dx.doi.org.cmich.idm.oclc.org/10.1016/j.jesp.2009.06.010

Fraser, A. M., Padilla-Walker, L., Coyne, S. M., Nelson, L. J., \& Stockdale, L. A. (2012). Associations between violent video gaming, empathic concern, and prosocial behavior toward strangers, friends, and family members. Journal of Youth and Adolescence, 41(5), 636-649. doi:http://dx.doi.org.cmich.idm.oclc.org/10.1007/s10964-012-9742-2

Gentile, D. A., Anderson, C. A., Yukawa, S., Ihori, N., Saleem, M., Ming, L. K., . . . Sakamoto, A. (2009). The effects of prosocial video games on prosocial behaviors: International evidence from correlational, longitudinal, and 
experimental studies. Personality and Social Psychology Bulletin, 35(6), 752-763. doi:http://dx.doi.org.cmich.idm.oclc.org/10.1177/0146167209333045

Glass, G. V., Peckham, P. V., \& Sanders, J. R. (1972). Consequences of Failure to Meet Assumptions Underlying the Fixed Effects Analyses of Variance and Covariance. Review of Educational Research, 42(3), 237-288. https://doi.org/10.3102/00346543042003237

Greitemeyer, T. (2014). Intense acts of violence during video game play make daily life aggression appear innocuous: A new mechanism why violent video games increase aggression. Journal of Experimental Social Psychology, 50, 52. Retrieved from http://cmich.idm.oclc.org/login?url=http://search.proquest.com.cmich.idm.oclc.org /docview/1465233147? accountid=10181

Greitemeyer, T., \& Mügge, D.,O. (2014). Video games do affect social outcomes: A meta-analytic review of the effects of violent and prosocial video game play. Personality and Social Psychology Bulletin, 40(5), 578. Retrieved from http://cmich.idm.oclc.org/login?url=http://search.proquest.com.cmich.idm.oclc.org /docview/1518748736?accountid=10181

Greitemeyer, T., \& Osswald, S. (2010). Effects of prosocial video games on prosocial behavior. Journal of Personality and Social Psychology, 98(2), 211-221. doi:http://dx.doi.org.cmich.idm.oclc.org/10.1037/a0016997

Greitemeyer, T., \& Osswald, S. (2011). Playing prosocial video games increases the accessibility of prosocial thoughts. The Journal of Social Psychology, 151(2), 121. Retrieved from 


\section{http://cmich.idm.oclc.org/login?url=http://search.proquest.com.cmich.idm.oclc.org}

\section{/docview/867773860?accountid=10181}

Hero Violence Dataset: https://github.com/Joe-Hilgard/hero-violence

Hilgard, J., Engelhardt, C. R., \& Rouder, J. N. (2017). Overstated evidence for shortterm effects of violent games on affect and behavior: A reanalysis of anderson et al. (2010). Psychological Bulletin, 143(7), 757-774.

doi:http://dx.doi.org.cmich.idm.oclc.org/10.1037/bul0000074

Hull, J. G., Brunelle, T. J., Prescott, A. T., \& Sargent, J. D. (2014). A longitudinal study of risk-glorifying video games and behavioral deviance. Journal of Personality and Social Psychology, 107(2), 300-325.

doi:http://dx.doi.org.cmich.idm.oclc.org/10.1037/a0036058

Kepes, S., Bushman, B. J., \& Anderson, C. A. (2017). Violent video game effects remain a societal concern: Reply to hilgard, engelhardt, and rouder (2017).Psychological Bulletin, 143(7), 775-782.

doi:http://dx.doi.org.cmich.idm.oclc.org/10.1037/bul0000112

Manucia, G. K., Baumann, D. J., \& Cialdini, R. B. (1984). Mood influences on helping: Direct effects or side effects? Journal of Personality and Social Psychology: Interpersonal Relations and Group Processes, 46(2), 357-364. doi:http://dx.doi.org.cmich.idm.oclc.org/10.1037/0022-3514.46.2.357

McCarthy, R. J., Coley, S. L., Wagner, M. F., Zengel, B., \& Basham, A. (2016). Does playing video games with violent content temporarily increase aggressive inclinations? A pre-registered experimental study. Journal of Experimental Social 
Psychology, 67, 13-19.

doi:http://dx.doi.org.cmich.idm.oclc.org/10.1016/j.jesp.2015.10.009

Morey, R. D., \& Rouder, J. N. (2015). BayesFactor 0.9. 12-2. Comprehensive R Archive Network.

Saleem, M., Anderson, C. A., \& Barlett, C. P. (2015). Assessing helping and hurting behaviors through the tangram Help/Hurt task. Personality and Social Psychology Bulletin, 41(10), 1345-1362.

doi:http://dx.doi.org.cmich.idm.oclc.org/10.1177/0146167215594348

Simmons, Joseph P. and Nelson, Leif D. and Simonsohn, Uri, A 21 Word Solution (October 14, 2012). Available at SSRN: $\underline{\text { https://ssrn.com/abstract=2160588 }}$ or http://dx.doi.org/10.2139/ssrn.2160 $\underline{588}$

Tear, M. J. \& Nielsen, M. (2013). Failure to demonstrate that playing violent video games diminishes prosocial behavior. Plos One, https://doi.org/10.1371/journal.pone.0068382

Watson, D., Clark, L. A., \& Tellegen, A. (1988). Development and validation of brief measures of positive and negative affect: The PANAS scales. Journal of Personality and Social Psychology, 54(6), 1063-1070. doi:http://dx.doi.org/10.1037/0022-3514.54.6.1063

Willoughby, T., Adachi, P. J. C., \& Good, M. (2012). A longitudinal study of the association between violent video game play and aggression among adolescents. Developmental Psychology, 48(4), 1044-1057. Retrieved from 
http://cmich.idm.oclc.org/login?url=http://search.proquest.com.cmich.idm.oclc.org /docview/901639869?accountid=10181

You, S., Kim, E., \& No, U. (2015). Impact of violent video games on the social behaviors of adolescents: The mediating role of emotional competence. School Psychology International, 36(1), 94. Retrieved from http://cmich.idm.oclc.org/login?url=http://search.proquest.com.cmich.idm.oclc.org /docview/1648678842?accountid=10181 